\title{
Duration and Predictors of Emergency Surgical Operations - Basis for Medical Management of Mass CASUALTY INCIDENTS
}

\author{
S. Huber-Wagner ${ }^{1}$, R. Lefering ${ }^{2}$, M. V. Kay ${ }^{1}$, J. Stegmaier ${ }^{1}$, P. N. Khalil ${ }^{1}$, A. O. Paul ${ }^{1}$, P. Biberthaler ${ }^{1}$, \\ W. Mutschler ${ }^{1}$, K.-G. Kanz ${ }^{1}$, on behalf of the Working Group on Polytrauma (NIS) of the German \\ Trauma Society (DGU)* \\ ${ }^{1}$ Munich University Hospital, Department of Trauma Surgery - Campus Innenstadt, Ludwig-Maximilians-University Munich, Germany \\ ${ }^{2}$ IFOM - Institute for Research in Operative Medicine, University Witten/Herdecke, Faculty of Medicine, Cologne, Germany
}

\begin{abstract}
Background: Hospitals have a critically important role in the management of mass causality incidents (MCI), yet there is little information to assist emergency planners. A significantly limiting factor of a hospital's capability to treat those affected is its surgical capacity. We therefore intended to provide data about the duration and predictors of life saving operations.

Methods: The data of 20,815 predominantly blunt trauma patients recorded in the Trauma Registry of the German-Trauma-Society was retrospectively analyzed to calculate the duration of life-saving operations as well as their predictors. Inclusion criteria were an ISS $\geq 16$ and the performance of relevant ICPMcoded procedures within $6 \mathrm{~h}$ of admission.

Results: From 1,228 patients fulfilling the inclusion criteria 1,793 operations could be identified as life-saving operations. Acute injuries to the abdomen accounted for $54.1 \%$ followed by head injuries $(26.3 \%)$, pelvic injuries (11.5\%), thoracic injuries (5.0\%) and major amputations (3.1\%). The mean cut to suture time was $130 \mathrm{~min}$ (IQR 65-165min). Logistic regression revealed 8 variables associated with an emergency operation: AIS of abdomen $\geq 3$ (OR 4,00), ISS $\geq 35$ (OR 2,94), hemoglobin level $\leq 8 \mathrm{mg} / \mathrm{dL}$ (OR 1,40), pulse rate on hospital admission $<40$ or $>120 / \mathrm{min}$ (OR 1,39), blood pressure on hospital admission $<90$ $\mathrm{mmHg}$ (OR 1,35), prehospital infusion volume $\geq 2000$ $\mathrm{ml}(\mathrm{OR} 1,34), \mathrm{GCS} \leq 8$ (OR 1,32) and anisocoria (OR 1,28) on-scene.

Conclusions: The mean operation time of $130 \mathrm{~min}$ calculated for emergency life-saving surgical operations provides a realistic guideline for the prospective treatment capacity which can be estimated and projected into an actual incident admission capacity. Knowledge of predictive factors for life-saving emergency operations helps to identify those patients that need most urgent operative treatment in case of blunt MCI.
\end{abstract}

Key words: Multiple casualty incidents, Mass casualty incident, MCI, Triage, Emergency operation, Lifesaving procedure, Emergency planning, Disaster medicine

\section{INTRODUCTION}

A mass casualty incident (MCI) is an infrequent event that requires coordinated action under time constraints [1]. In the last years, beside natural disasters, transportations and structure failure incidents, terrorist bombings have emerged to be a particularly devastating and medically challenging type of a MCI $[2,3]$. The sudden influx of patients seeking similar medical interventions strains critical hospital facilities and resources [1].

Aside from incident scene operations such as triage treatment and transport, hospital operations such as trauma room resuscitation, computed tomography (CT) and the intensive care unit (ICU) capacity, another major bottleneck in the management of a mass casualty incident (MCI) is operational surgical treatment capacity $[1,4,5]$. Despite the significance of this restriction in a chain of processes, there is little data available in the literature about the duration or predictors.

Predictive resource planning is an important factor in risk management. For planners to conduct scenario analysis and develop operational procedures, basic parameters are essential [6]. At the entity level, the inhospital management of a MCI must take the number of available surgical operation teams as well as the expected duration of life-saving emergency operations into account [4]. Furthermore it is important to consider that time of the incident has potential impact on the availability of personnel and therefore on the treatment capacity of trauma centers. Outside of normal operating hours the situation has to be managed initially by in-house and regular background staff only. At local, state and federals levels indications of how and when an emergency response system may be overwhelmed can help plan investment and emergency response policy.

The goal of this study is to analyze the data collected by the Trauma Registry of the German Trauma Society and calculate the mean duration and distribution pattern of life-saving operations as well as their predictors. This information is of potential use if one as- 
sumes that injury patterns and individual surgical times would be the same in the event of an MCI. Thus these parameters could help to plan and optimize pre-hospital patient distribution and prioritized in-hospital treatment of MCI victims. It can also help to determine surge capacities.

\section{Methods}

\subsection{Data Collection}

The Trauma Registry of the German Trauma Society was initiated in 1993 by the society's “Working Group on Polytrauma" to collect data of polytrauma victims within German-speaking countries (Germany, Austria and Switzerland) [7].

This trauma registry is a prospective, multicenter, standardized and anonymized documentation of severely injured patients. Parameters of the prehospital and trauma room (TR) treatment as well as of the subsequent intensive care unit course are continuously inputted to a web-based data server. The data that is entered is based on a standard codebook that defines each data element. The data are checked for plausibility before they are finally entered and included into the database. Every trauma patient admitted to one of the 100 participating trauma hospitals** with an ISS $\geq 16$ (Injury severity score) or who receives ICU (intensive care unit) treatment or who dies in the trauma room is documented for the registry. Data is submitted to a central database hosted by the Institute for Research in Operative Medicine (IFOM) at the University of Witten/Herdecke in Cologne, Germany. Data anonymity is guaranteed both for the individual patient and the participating hospital. The registry constitutes epidemiologic, physiologic, laboratory, diagnostic, operative, interventional and intensive care medical data as well as scoring and outcome data [8-10]. The content of the database in 2005, comprising of 20,815 patients from 1993 to 2004 with a mean ISS of 24.0, was analyzed.

Inclusion criteria were:

- ISS $\geq 16$,

- emergency operation within 6h after hospital admission and

- available information on the beginning and duration of the operation.

Patients transferred from other hospitals were excluded.

The criteria of a life-saving operations were as follows (modified according to Garner et al. [11]):

- Relevant, life-saving operation at the head, thorax, abdomen, pelvis or major amputation of the limbs,

exclusion of minor interventions as insertion of a intracranial pressure catheter (ICP), insertion of a chest tube or laparoscopy,

- exclusion of orthopaedic operations at the spine or the limbs with exception of major amputations.

All operations within the Trauma Registry are documented as ICPM-codes (International Classification of Procedures in Medicine, version 1.1). The emergency operations were identified according to the ICPMcodes given in Table in the appendix.

\subsection{Statistical ANALYSIS}

Retrospective statistical analysis was performed in two steps. First, a descriptive data analysis was performed, second, a logistic regression model was calculated. The following parameters were used to perform a descriptive data analysis.

\section{Prehospital:}

Trauma mechanism, age, sex, pulse rate, blood pressure, rate of patients in shock (blood pressure onscene $<90 \mathrm{mmHg}$ ), intubation rate on scene, rate of chest tube insertion on-scene, GCS (Glasgow Coma Scale), infusion volume and time from accident to hospital admission.

\section{Trauma Room:}

Pulse rate, blood pressure on admission, rate of patients in shock, base excess, hemoglobin concentration, thromboplastin time, number of packed red blood cells (PRBC) transfused, infusion volume in trauma room until ICU and rate of computed tomographies performed.

Intensive Care Unit:

ISS, New ISS (NISS), pattern of injuries (abbreviated injury severity score, AIS $\geq 3$ ), TRISS (Trauma and injury severity score), rate of multi organ failure (MOF, defined as organ failure of two systems of $>2$ SOFAscore points of at least 2 days duration [12]), ventilation days, ICU length of stay, hospital length of stay and survival rate (defined as survival to discharge).

The following parameters were dichotomized for bivariate and multivariate logistic regression analysis:

\section{Prehospital:}

Age $\geq 75$ versus $<75$ years, female versus male gender, non-insertion of chest tube vs. insertion of chest tube, non-performance vs. performance of closed chest cardiac massage, pulse rate $\leq 39$ or $\geq 120 / \mathrm{min}$ versus $40-120 / \mathrm{min}$, blood pressure $>90$ versus $\leq 90$ $\mathrm{mmHg}$, GCS on scene $>8$ versus $\leq 8$, isocoria vs. anisocoria of the pupils and infusion volume $\geq 2000$ $\mathrm{ml}$ versus $<2000 \mathrm{ml}$.

\section{Trauma Room:}

Non-performance versus performance of closed chest cardiac massage, pulse rate $\leq 39$ or $\geq 120 / \mathrm{min}$ versus $40-120 / \mathrm{min}$, blood pressure $>90$ versus $\leq 90 \mathrm{mmHg}$, hemoglobin concentration $>8$ versus $\leq 8 \mathrm{mg} / \mathrm{dL}$, thromboplastin time $>50 \%$ versus $\leq 50 \%$, ISS $\geq 25$ versus $<25$, ISS $\geq 35$ versus $<35$ and AIS head, thorax, abdomen and extremities respectively $\geq 3$ versus $<3$.

After dichotomisation a bivariate analysis followed by a logistic regression model with life-saving emergency operation within $6 \mathrm{~h}$ after hospital admission as the target variable was calculated. The 20 variables listed above were entered into a stepwise multivariate logistic regression model (stepwise forward elimination) to identify independent risk factors for an emergency operation by calculating odds ratios for each factor as well as 95\% confidential intervals (CI 95\%). Statistical significance was assessed at $\mathrm{p}<0.05$. Statistical analy- 
sis was performed using SPSS Version 15.0 (SPSS Inc., Chicago, IL, USA).

This study has the full approval of the ethics committee of the Ludwig-Maximilians-University (LMU) of Munich, Germany.

\section{RESULTS}

Amongst the 20,815 patients in the Trauma Registry 9,988 had complete data according to the inclusion criteria. Included in these 9,988 patients were 7,907 who received an operation (non-emergency and emer- gency) within 6h after hospital admission. Of those, 1,228 patients $(12.3 \%)$ underwent 1,793 life-saving emergency operations fulfilling the criteria mentioned above, i.e. 1.5 emergency procedures per patient (separate operations or multiple operative procedures during one operating room visit). Table 1 demonstrates the main characteristics of the investigated 1,228 patients.

Table 2 demonstrates time and proportion of the emergency operation with respect to the affected body system. Acute injuries of the abdomen required an urgent emergency operation in $54.1 \%$ of the 1,793

Table 1. Characteristics of 1,228 trauma patients with emergency operation.

Characteristic

Patients in Trauma Registry

Patients fulfilling inclusion criteria

Patients with emergency operation within 6 hours (n)

Number of emergency operations

Blunt injury

Age (years)

Male gender

Intubation rate prehospital

Prehospital

Chest tube insertion on-scene

Pulse rate on-scene (beats/ $\mathrm{min}$ )

Blood pressure on-scene $(\mathrm{mmHg})$

Shock on-scene (blood pressure $<90 \mathrm{mmHg}$ )

Prehospital infusion volume $(\mathrm{ml})$

Closed chest cardiac massage on-scene

GCS on-scene (points)

GCS $\leq 8$ on-scene

Anisocoria on-scene

Time from accident to hospital admission (min)

\section{Trauma room/in-hospital}

Pulse rate on TR admission (beats/min)

Blood pressure on TR admission $(\mathrm{mmHg})$

Shock on TR admission (blood pressure $<90 \mathrm{mmHg}$ )

Base excess in TR

Hemoglobin concentration in TR $(\mathrm{g} / \mathrm{dL})$

Thromboplastin time in TR $(\%)$

Number of PRBC transfused until ICU

Infusion volume in TR until ICU (ml)

Computed tomography in trauma room

Ventilation length of time, ICU (days)

ICU length of stay (days)

Hospital length of stay (days)

ISS (points)

New ISS (points)

AIS head $\geq 3$

AIS thorax $\geq 3$

AIS abdomen $\geq 3$

AIS extremities $\geq 3$

Mortality rate

Early mortality rate $(<24 \mathrm{~h})$

\section{Number(Percent) or Mean \pm SD}

$$
\begin{gathered}
20,815 \\
9,988 \\
1,228 \\
1,793 \\
1158(94.3 \%) \\
37.1 \pm 17.9 \\
868(70.7 \%) \\
922(75.1 \%) \\
\\
128(10.4 \%) \\
99 \pm 26.2 \\
106 \pm 36.4 \\
429(34.9 \%) \\
2,079 \pm 1.461 \\
41(3.3 \%) \\
9 \pm 5.0 \\
597(48.6 \%) \\
183(14.9 \%) \\
68.0 \pm 33.0 \\
\\
95 \pm 25.2 \\
109 \pm 34.8 \\
368(30.0 \%) \\
-5.1 \pm 6.3 \\
9.9 \pm 3.8 \\
65.4 \pm 25.6 \\
9.5 \pm 11.4 \\
5,246 \pm 6172 \\
799(65.1 \%) \\
10.8 \pm 14.1 \\
15.4 \pm 17.1 \\
28.2 \pm 31.0 \\
36.5 \pm 13.8 \\
42.8 \pm 14.2 \\
678(55.2 \%) \\
717(58.4 \%) \\
679(55.3 \%) \\
578(47.1 \%) \\
381(31.0 \%) \\
192(15.6 \%)
\end{gathered}
$$

GCS, Glasgow Coma Scale; TR, Trauma Room; PRBC, packed red blood cells; ISS, Injury Severity Score; ICU, Intensive Care Unit; AIS, abbreviated injury scale. 
Table 2. Time and Proportion of the 1,793 emergency operations in 1,228 patients.

\begin{tabular}{|c|c|c|c|c|}
\hline Region & Operations & $\%$ & Mean Cut to suture time [min] & IQR [min] \\
\hline Head & 472 & 26.3 & 110 & $55-140$ \\
\hline Thorax & 90 & 5.0 & 91 & $8-146$ \\
\hline Abdomen & 970 & 54.1 & 137 & $70-175$ \\
\hline Pelvis & 206 & 11.5 & 136 & $60-185$ \\
\hline Extremities & 55 & 3.1 & 142 & $80-180$ \\
\hline Overall & 1,793 & 100 & 130 & $65-165$ \\
\hline
\end{tabular}

IQR, Interquartile range.

emergency operations. The mean operation length of time (cut to suture) was $137 \mathrm{~min} .26 .3 \%$ of the emergency operations were performed because of severe head injury, mean operation time was 110 min. 11.5\% of the operations accounted for pelvic injuries with a mean operation time of $136 \mathrm{~min}, 5.0 \%$ for thoracic injuries with 91 min mean operation length and 3.1\% for severe limb injury with a mean duration of $130 \mathrm{~min}$. The mean cut to suture time for all investigated operations was $130 \mathrm{~min}$.

Table 3 shows the predictive factors for an emergency operation according to the results of our logistic regression model. The highest probability for a life-saving emergency operation (i.e. odds ratio, OR $>1$ ) is an AIS of the abdomen of equal or more than 3 , followed by high ISS, low hemoglobin concentration, pathologic pulse rate, shock on hospital admission, high prehospital infusion amount, low GCS and anisocoria.
An AIS of the extremities $\geq 3$, high age, closed chest cardiac massage on-scene and an AIS of the tho$\operatorname{rax} \geq 3$ are predictors for non-performance of lifesaving emergency operations $(\mathrm{OR}<1)$.

\section{Discussion}

Providing for the security of the citizen does not stop when preventative measures have been applied. Security also encompasses protection against the negative consequences of a destructive event should preventative measure fail. Proactive or "emergency" planning should be undertaken by organization governments and entities alike as the basis for implementing adequate measures to reduce the magnitude of loss caused by those events that could not be averted. The health sector is not exempt from this responsibility.

Table 3. Predictors for life-saving Emergency Operations.

\begin{tabular}{|c|c|c|c|c|}
\hline Variable & Regression coefficient & $\begin{array}{c}\text { Odds ratio (OR) } \\
\mathrm{e}^{\beta}\end{array}$ & Confidence interval 95\% & $\mathrm{p}$ value \\
\hline AIS Abdomen $\geq 3$ & 1.38 & 4.0 & 3.3-4.7 & $<0.001 *$ \\
\hline ISS $\geq 35$ & 1.08 & 2.9 & $2.3-3.8$ & $<0.001 *$ \\
\hline ISS $\geq 25$ & 0.68 & 2.0 & $1.6-2.5$ & $<0.001 *$ \\
\hline Hemoglobin $\leq 8 \mathrm{mg} / \mathrm{dL}$ & 0.34 & 1.4 & $1.1-1.7$ & $0.002 *$ \\
\hline $\begin{array}{l}\text { Pulse on hospital admission } \\
\leq 39 \text { or } \geq 120 / \mathrm{min}\end{array}$ & 0.33 & 1.4 & $1.1-1.8$ & $0.011 *$ \\
\hline $\begin{array}{l}\text { Shock on TR admission } \\
\quad \text { RR }<90 \mathrm{mmHg}\end{array}$ & 0.30 & 1.4 & $1.1-1.7$ & $0.004 *$ \\
\hline $\begin{array}{l}\text { Prehospital infusion volume } \\
\quad \geq 2000 \mathrm{ml}\end{array}$ & 0.30 & 1.3 & $1.2-1.6$ & $0.001 *$ \\
\hline $\mathrm{GCS} \leq 8$ & 0.26 & 1.3 & $1.1-1.6$ & $0.003^{*}$ \\
\hline Anisocoria on-scene & 0.25 & 1.3 & $1.0-1.6$ & $0.039 *$ \\
\hline AIS extremities $\geq 3$ & -0.19 & 0.8 & $0.7-0.9$ & $0.030^{*}$ \\
\hline Age $>75$ years & -0.48 & 0.6 & $0.4-0.9$ & $0.016^{*}$ \\
\hline $\begin{array}{l}\text { Closed chest cardiac massage } \\
\text { on-scene }\end{array}$ & -0.53 & 0.6 & $0.4-0.9$ & $0.024 *$ \\
\hline AIS thorax $\geq 3$ & -0.67 & 0.5 & $0.4-0.6$ & $<0.001 *$ \\
\hline Constant & -2.925 & 0.05 & - & $<0.001 *$ \\
\hline
\end{tabular}

AIS, abbreviated injury scale; ISS, Injury Severity Score; TR, Trauma Room; GCS, Glasgow Coma Scale.

Logistic regression model (stepwise forward, 12 steps) based on $n=6,145$ patients. The model was calculated with the above listed 20 starting variables. 
The terrorist bombings in Madrid 2004 and London 2005, with an overall number of about 2,700 casualties and 245 deaths, emphasizes the relevance of being prepared for such possible MCIs [13, 14]. Preparations for major events, such as the soccer world cup, entail planning for the management of mass casualty incidents.

The in-hospital management of a MCI can not occur "ad hoc" and must be planned. To estimate the treatment capacity of a hospital, the available resources as well as approximative data about the distribution and duration of life-saving emergency operations are basic requirements.

In this study, we analyzed the Trauma Registry of the German Trauma Society. The collective represents severe blunt trauma victims requiring emergency surgery expressed by a mean ISS of 36.5. The collective is thus comparable to those victims that are critically injured within a MCI. The mean ISS of the critically injured patients in the Madrid bombings for example was 34 [13]. The fraction of patients with an ISS $\geq 16$ consecutive to terrorist bombing are reported to range from $15 \%$ and $30.5 \%$ related to the overall number of victims [15-19].

Garners analyses of 1,144 trauma patients measured the accuracy of different MCI triage algorithms. Their aim was to find out predictors for "critical injury" which was defined as the requirement for nonorthopedic operative procedure within $6 \mathrm{~h}$ after admission. These procedures included thoracotomy, laparotomy, craniotomy or fluid resuscitation of $>1000 \mathrm{ml}$ due to hypotension, transfusion, requirement for invasive central nervous system monitoring or the necessity for airway management, requirement for assisted ventilation or decompression of a tension pneumothorax. Garner identified 135 (11.8\%) critically injured patients fulfilling one or more of these criteria. 49 $(4.3 \%)$ required emergency surgery [11].

We specified these criteria defining a life-saving operation as a relevant operation (ICPM-coded) at the head, thorax, abdomen, pelvis or extremities in case of major amputation within $6 \mathrm{~h}$ after hospital admission excluding minor interventions and orthopedic operations. We were able to identify 1,228 major trauma patients that underwent life-saving surgery which is to the best of our knowledge the highest number of such patients that has yet been analysed. Our study population is comparable to the 49 patients and with some reservations also to the 135 critically injured reported by Garner [11]. To estimate the operation capacity in the case of a MCI, it can be assessed that approximately one third of the critically injured patients coded as "red", according to the "simple triage and rapid treatment" concept (START), require life-saving emergency surgery [11, 20, 21].

Our analysis of the Trauma Registry demonstrated that $12.3 \%$ of the investigated 9,988 patients underwent 1,793 emergency operations. This means that at an average every patient required 1.5 emergency operations.

It can be assumed that our investigated collective is comparable to patients coded as "red" in the START concept. This assumption is based on the high prehospital intubation rate, high rate of patients in shock, high rate of patients that were in deep unconsciousness, a high prehospital infusion rate, and a high injury severity score.

To the best of our knowledge there is nearly no data in the literature measuring the duration of an emergency operation of MCI or non-MCI trauma patients. Morales et al. investigated 762 abdominal trauma patients to identify predictors for intra-abdominal infection. They report on a mean operation time of 120 minutes in their cohort [22].

Hirshberg et al. performed a computer simulation to estimate the mean surge capacity of a Level I trauma center after a terrorist bombing. They empirically estimated the operation time for general trauma to be $129 \mathrm{~min}$ [4]. They calculated that an average of 4.6 major trauma patients per hour could be managed by a Level I trauma center during a MCI.

The analysis performed in this study demonstrated a mean cut to suture time of $130 \mathrm{~min}$ for a life-saving emergency operation. Based on this time (amongst many other factors) hospitals preparing for a MCI can plan and calculate their surge capacity, in particular their operative (surgical) capacities.

The distribution of the identified emergency operations to different body regions helps to estimate the surgical disciplines required to cope with a MCI. Most of the operations were related to the abdomen (general surgeons), followed by the head (neurosurgeons), pelvis and extremities (orthopaedic surgeons) and the thorax (general or thoracic surgeon).

Based upon this distribution it can surmised that an urban environment has at least the functional facilities to manage an MCI, with the exception of neurosurgery where departments may be overstrained. Rural environments could be lacking in general-, orthopedicand thoracic surgical facilities.

Turegano-Fuentes et al. report on $32.3 \%$ orthopedic operations, $16.9 \%$ plastic reconstructive, $13.7 \%$ general abdominal and on $8.9 \%$ neurosurgical operations consecutive to the Madrid bombings in 2004. They did not discriminate between non life-saving operations and life-saving emergency operations. The body regions predominantly affected were face $(56.8 \%)$, followed by chest $(38.9 \%)$, extremities $(13.9 \%)$ and the abdomen (5.5\%) [23]. This pattern is different to that we observed in our collective (see limitations).

Kluger et al. demonstrated that the distribution pattern of required surgery of bombing victims differs significantly from "conventional" trauma $(p<0.001)$. They found $21.2 \%$ orthopaedic operations, $12.7 \% \mathrm{ab}-$ dominal, $6.7 \%$ neurosurgical and 6.2\% thoracic operations [16]. The pattern of injuries after a terrorist bombing attack reported by Peleg et al. is also different to ours. They report on $30.8 \%$ head injuries, $30.8 \%$ thoracic, $19.2 \%$ abdominal injuries and 19.2\% combinations whereas we found the abdominal and head injuries to be leading [19]. In his study from 2004 Peleg et al. focuse on gunshot and explosion injuries describing injuries of the extremities to be most frequently, followed by injuries to the head, chest and the abdomen [18].

The presented distribution pattern of emergency operations of our study can help hospitals to prepare 
for predominantly blunt MCIs such as transport accidents, by addressing the necessary provision and presence of the most relevant surgical disciplines.

To identify independent predictors for an emergency operation a logistic regression model was calculated. The highest probability indicating the need for a life-saving emergency operation (i.e. odds ratio/OR > 1) is a high AIS of the abdomen, followed by high ISS, low hemoglobin concentration, pathologic pulse rate, shock on hospital admission, high prehospital infusion amount, low GCS and anisocoria. Low hemoglobin levels can either represent ongoing bleeding and/or dilution effects consecutive to prehospital volume treatment.

Contrary, an AIS of the extremities $\geq 3$, high age, closed chest cardiac massage on-scene and an AIS of the thorax $\geq 3$ are predictors for non-performance of life saving emergency operations $(\mathrm{OR}<1)$. This may be explainable by the fact that injuries to the extremities are rather limb or joint threatening than really life threatening in most of the cases. High age of more than 75 years seems to be an indicator for a poor outcome and therefore indicating that the medical team should consider not to do all that might be technically possible if this would clearly jeopardize other patients with good predicted outcomes.

In the same way, the necessity to administer closed chest cardiac massage on-scene may be a factor to consider when deciding to apply possible emergency operations.

The fact that injuries of the thorax (AIS $\geq 3$ ) are not associated with life saving emergency operations may be explained because the most frequent of these injuries, such as pneumo- and/or hemothoraces, can be successfully treated by chest tube insertion in most of the cases. Chest tube insertion was defined to be a minor intervention and did not account for life-saving emergency operations (see exclusion criteria). Rib fractures and lung contusions can be treated adequately on an intensive care unit without surgical intervention.

To the best of our knowledge there is little data in the literature providing predictive factors for emergency operations in major trauma patients. Lipsky et al. report prehospital hypotension to be a predictor of the need for an emergency operation in trauma patients showing normal blood pressure at hospital admission ( $n=1,067$ ) [24]. Our data underlines the role of shock at hospital admission as a prognostic factor for operative intervention.

Almogy et al. calculated the following predictors indicating intra-abdominal injury with consecutive emergency operation: Penetrating torso injury and injury to four or more anatomic body regions [25]. In another study Almogy et al. calculated burns, open fractures and amputations to be predictors for death of terror victims [26]. Frykberg underlines the importance of being able to perform emergency operations by highlighting the "immediate presence of surgeons" as one of the most relevant prognostic factors affecting casualty outcome after terrorist bombing [27].

The presented predictors of our analysis may be of use to the medical teams on-scene and in the emergency departments in quickly identifying those patients who require urgent emergency surgery. The fac- tors pathologic pulse rate, shock on hospital admission, high prehospital infusion amount, low GCS and anisocoria can be easily checked on-scene or immediately after trauma room admission. The AIS of the abdomen and the ISS can be estimated after sonography, $\mathrm{X}$-ray or computed tomography. Low hemoglobin concentration can be quickly confirmed by early blood gas analysis. Thus the knowledge, awareness and registration of the predictors mentioned above can guide the decision to carry out life-saving emergency operations on critically injured blunt trauma victims during MCI.

We would like to emphasize the importance of abdominal injury. In our study an AIS $\geq 3$ (OR 4.0) was a strong indicator of the target variable "life-saving emergency operation". In our opinion this justifies evaluating focused abdominal sonography for trauma (FAST) as on scene activity. There is strong evidence that FAST is an effective, safe, quick and reliable tool with good rates of sensitivity $(83 \%)$ and specificity (98\%), even in the prehospital setting [28-31]. According to the AIS-2005-dictionary free fluid - the main interest of FAST - can be expected in injuries of the abdomen with an AIS $\geq 3$ [32].

This could be used to quickly identify patients who must receive expedient transport to a surgical facility but were not identified at an earlier stage of the triage process. Thus FAST could be included in a MCI algorithm as a triage activity and tasked to trained physicians and paramedics. On hospital admission FAST should then be repeated in order to decide which patient requires further evaluation by multi-slice-computed tomography (MSCT) or immediate operation.

Patients with low GCS and/or pupillary dysfunction should also be selected for early MSCT (accelerated triage protocol) to detect major head injury [33]. This would help to distribute the CT capacity which is one of the above mentioned bottlenecks in the management of MCI. CT could thus be implemented rationally as a triage tool [33].

There are several limitations of our study. The first is that our study is not prospective, a prospective design, however, is difficult to implement in mass casualty medicine.

Next, our data is predominantly from patients who have sustained blunt injury. The implications of our findings cannot be transferred to penetrating injuries. It has been demonstrated that bombings results in specific multidirectional injury patterns due to the blast and the projectiles [16]. Our results could primarily contribute to optimize the planning and preparation of the in-hospital management of mass casualty patients who have suffered blunt injury as for example after natural disasters, transportation and structure failure incidents, specifically earthquakes, tornados and hurricanes. It cannot be estimated how far a "standard" blunt major trauma victim is comparable to a blunt MCI patient.

Due to our detailed inclusion criteria only 9,988 of the 20,815 patients comprised in the trauma registry could be used for our analysis. Due to missing data in our registry, the logistic regression model could only be performed with $62 \%$ of the 9,988 patients. This might bias the results. 
Another fact that might bias our results is the fact that patients that die on-scene are not recorded in the registry.

As the participating hospital was free to choose its own algorithmic work-up, there were no clear and consistent indications for or against emergency operations. This may also bias our findings. Due to the structure of the registry there is no detailed information on operational differences in the participating hospitals. Furthermore we do not know which hospital has implemented the principles of ATLS $^{\circledR}$ and to which extent.

Potentially different inter-center consistency in grading injuries (AIS, ISS) may also bias our data. There are significant organizational and structural differences depending on the region and the federal state in Germany. This might have additional and unquantifiable influence on our results.

Despite these limitations, our results indicate that the average cut to suture time of a life-saving emergency operation in blunt major trauma patients is 130 min. Supposing that trauma victims coded as "red" refer to critically injured patients, at least every 5th case requires life-saving emergency surgery. Every second operation will be at the abdomen, every fourth at the skull. Knowledge of this information provides a realistic guideline for the prospective treatment capacity, which can be estimated and projected into an actual incident admission capacity.

In conclusion, the predictors high AIS of the abdomen, high ISS, low hemoglobin concentration, pathologic pulse rate, shock on hospital admission, high prehospital infusion amount, low GCS and anisocoria indicate high probability of a necessary life-saving emergency operation in blunt trauma / MCI victims. They can be attained early and easily and could be incorporated into a MCI triage algorithm.

The implementation of FAST at a MCI scene and at hospital admission should be further evaluated and discussed. As the surgical operation capacity is one of the critical bottlenecks of a hospital in the MCI management process, our findings may contribute to increase the effectiveness of planning for both in-hospital and general management of a blunt mass casualty incident.

\section{Statements:}

1. There are no conflicts of interest.

2. There was no funding for this particular study, however, the Trauma Registry of the German Trauma Society (Deutsche Gesellschaft für Unfallchirurgie, DGU) in general was partly funded by the Deutsche Forschungsgemeinschaft (DFG) Ne $385 / 5$ and by a grant of Novo Nordisk A/S, Bagsvaerd, Denmark.

3. I, Dr Huber-Wagner (corresponding author), declare that I had full access to all the data in the study and had final responsibility for the decision to submit for publication.

\section{Acknowledgements:}

* Working group on Polytrauma - German Trauma Society (DGU) (alphabetic)

(Sektion Notfall-, Intensivmedizin und Schwerverletztenversorgung - NIS - der DGU)

Chairmen: A Seekamp and S Ruchholtz; chairmen of working subgroup “Trauma Registry”: R Lefering and Th Paffrath.

\section{** Participating hospitals (alphabetic):}

Universitätsklinik der RWTH Aachen; Zentralklinikum Augsburg; Kreiskrankenhaus Bad Hersfeld; Charité, Campus-Virchow-Klinikum Berlin; Martin-Luther-Krankenhaus Berlin; Klinikum Berlin-Buch; BG-Unfallklinik Berlin-Mahrzahn; Krankenanstalten Gilead Bielefeld; BG-Klinik Bochum Bergmannsheil; Knappschaftskrankenhaus, Ruhr-Universität Bochum; Friedrich-Wilhelms-Universität Bonn; Zentralkrankenhaus Sankt-Jürgen-Straße Bremen; Zentralkrankenhaus Bremen Ost; Klinikum Bremerhaven-Reinkenheide; Allgemeines Krankenhaus Celle; Klinikum Chemnitz; Klinikum Dessau; Klinikum Lippe-Detmold; Krankenhaus DresdenNeustadt; Technische Universität Dresden; Krankenhaus Dresden-Friedrichstadt; Heinrich-Heine-Universität Düsseldorf; Klinikum Erfurt; Kreiskrankenhaus Eschwege; Universitätsklinikum Essen; Evangelisches Krankenhaus Lutherhaus Essen; BG Unfallklinik Frankfurt/Main; Universitätsklinik Frankfurt/Main; Klinikum Frankfurt/Oder; Klinikum Fürth; Johanniter-Krankenhaus Geesthacht; Städtisches Klinikum Görlitz; Klinik am Eichert Göppingen; Georg-August-Universität Göttingen; Universität Graz (Österreich); Allgemeines Unfallversicherungsanstalt Graz (Österreich); Kreiskrankenhaus Grevenbroich; Universitätsklinik Groningen (Niederlande); Kreiskrankenhaus Gummersbach; BG-Unfallkrankenhaus Hamburg; Kreiskrankenhaus Hameln; Medizinische Hochschule Hannover; Krankenhaus HannoverNordstadt; Friederikenstift Hannover; Evangelisches Krankenhaus Hattingen; Orthopädische Universitätsklinik Heidelberg; St. Bernward Krankenhaus Hildesheim; Universität des Saarlandes Homburg/Saar; Waldviertel Klinikum Horn (Österreich); LKH Judenburg-Knittelfeld (Österreich); Städtisches Klinikum Karlsruhe; Universitätsklinikum Schleswig Holstein, Campus Kiel; Chirurgischer Lehrstuhl, Universität zu Köln; Städtisches Klinikum Köln-Merheim; Allgemeines öffentliches Krankenhaus Krems/Donau (Österreich); Städtisches Klinikum St. Georg, Universität Leipzig; Evangelisches Krankenhaus Lengerich; Allgemeines öffentliches Krankenhaus Linz (Österreich); Evangelisches Krankenhaus Lippstadt; Universitätsklinikum Schleswig Holstein, Campus Lübeck; BG Unfallklinik Ludwigshafen; St.-Marien-Hospital Lünen, Krankenhaus Altstadt; Städtisches Klinikum Magdeburg, Otto-von-Guericke-Universität Magdeburg; JohannesGutenberg-Universität Mainz; Universitätsklinikum Mannheim; Universität Marburg; Klinikum Minden; Krankenhaus Maria Hilf Mönchengladbach; Klinikum Großhadern, LMU München; Klinikum Innenstadt, LMU München; Städtisches Krankenhaus München-Harlaching; Westfälische WilhelmsUniversität Münster; BG-Unfallklinik Murnau; Lukaskrankenhaus, Städtisches Kliniken Neuss; Marienhospital Osnabrück; Vogtland Klinikum Plauen; Klinikum Remscheid; Klinikum Rosenheim; Sana-Krankenhaus Rügen; St. Johannes-Spital, Landeskrankenhaus Salzburg (Österreich); Diakonissenkrankenhaus Schwäbisch Hall; Kreiskrankenhaus Soltau; Johanniter-Krankenhaus der Altmark Stendal; Kreiskrankenhaus Traunstein; BG-Unfallklinik Tübingen; Bundeswehrkrankenhaus Ulm; Universitätsklinik Ulm; Klinikum der Stadt Villingen-Schwenningen; Klinikum Weiden/ Oberpfalz; Asklepios Kreiskrankenhaus Weißenfels; Donauspital Wien (Österreich); Ferdinand-Sauerbruch-Klinikum Wuppertal; Julius-Maximilians-Universität Würzburg; Universitätsspital ETH Zürich (Schweiz); Rettungsstelle Zusmarshausen.

\section{REFERENCES}

1. Hirshberg A, Stein M, Walden R. Surgical resource utilization in urban terrorist bombing: a computer simulation. J Trauma. 1999 Sep;47(3):545-50.

2. Frykberg ER, Tepas JJ, 3rd. Terrorist bombings. Lessons learned from Belfast to Beirut. Ann Surg. 1988 Nov; 208(5):569-76. 
3. Mallonee S, Shariat S, Stennies G, Waxweiler R, Hogan $\mathrm{D}$, Jordan F. Physical injuries and fatalities resulting from the Oklahoma City bombing. Jama. 1996 Aug 7;276(5): 382-7.

4. Hirshberg A, Scott BG, Granchi T, Wall MJ, Jr., Mattox KL, Stein M. How does casualty load affect trauma care in urban bombing incidents? A quantitative analysis. J Trauma. 2005 Apr;58(4):686-93; discussion 694-5.

5. Stein M, Hirshberg A, Gerich T. Mass casualties after an explosion. Unfallchirurg. 2003 Oct;106(10):802-10.

6. Hirshberg A, Holcomb JB, Mattox KL. Hospital trauma care in multiple-casualty incidents: a critical view. Ann Emerg Med. 2001 Jun;37(6):647-52.

7. Trauma register of the German Society of Trauma Surgery. "Scoring" study committee of the German Society of Trauma Surgery. Unfallchirurg. 1994 Apr;97(4): 230-7.

8. Ruchholtz S. The Trauma Registry of the German Society of Trauma Surgery as a basis for interclinical quality management. A multicenter study of the German Society of Trauma Surgery. Unfallchirurg. 2000 Jan;103(1):30-7.

9. Ruchholtz S. External quality management in the clinical treatment of severely injured patients. Unfallchirurg. 2004 Oct;107(10):835-43.

10. Ruchholtz S, Nast-Kolb D, Waydhas C, Lefering R. The trauma register of the 'Polytrauma' Committee of the German Society of Trauma Surgery as the basis for quality management in the management of severely injured patients. Langenbecks Arch Chir Suppl Kongressbd. 1997;114:1265-7.

11. Garner A, Lee A, Harrison K, Schultz CH. Comparative analysis of multiple-casualty incident triage algorithms. Ann Emerg Med. 2001 Nov;38(5):541-8.

12. Vincent JL, Moreno R, Takala J, Willatts S, De Mendonca A, Bruining H, Reinhart CK, Suter PM, Thijs LG. The SOFA (Sepsis-related Organ Failure Assessment) score to describe organ dysfunction/failure. On behalf of the Working Group on Sepsis-Related Problems of the European Society of Intensive Care Medicine. Intensive Care Med. 1996 Jul;22(7):707-10.

13. Gutierrez de Ceballos JP, Turegano Fuentes F, Perez Diaz D, Sanz Sanchez M, Martin Llorente C, Guerrero Sanz JE. Casualties treated at the closest hospital in the Madrid, March 11, terrorist bombings. Crit Care Med. 2005 Jan;33(1 Suppl):S107-12.

14. Lockey DJ, Mackenzie R, Redhead J, Wise D, Harris T, Weaver A, Hines K, Davies GE. London bombings July 2005: the immediate pre-hospital medical response. Resuscitation. 2005 Aug;66(2):ix-xii.

15. Stein M, Hirshberg A. Medical consequences of terrorism. The conventional weapon threat. Surg Clin North Am. 1999 Dec;79(6):1537-52

16. Kluger Y, Peleg K, Daniel-Aharonson L, Mayo A. The special injury pattern in terrorist bombings. J Am Coll Surg. 2004 Dec;199(6):875-9.

17. Almogy G, Rivkind AI. Surgical lessons learned from suicide bombing attacks. J Am Coll Surg. 2006 Feb;202(2):313-9.

18. Peleg K, Aharonson-Daniel L, Stein M, Michaelson M, Kluger Y, Simon D, Noji EK. Gunshot and explosion injuries: characteristics, outcomes, and implications for care of terror-related injuries in Israel. Ann Surg. 2004 Mar;239(3):311-8.

19. Peleg K, Aharonson-Daniel L, Michael M, Shapira SC. Patterns of injury in hospitalized terrorist victims. Am J Emerg Med. 2003 Jul;21(4):258-62.

20. Benson M, Koenig KL, Schultz CH. Disaster triage: START, then SAVE--a new method of dynamic triage for victims of a catastrophic earthquake. Prehospital Disaster Med. 1996 Apr-Jun;11(2):117-24.

21. Super G, Groth S, Hook R. START: Simple triage and rapid treatment plan. Hoag Memorial Hospital Presbyterian. 1994.
22. Morales CH, Villegas MI, Villavicencio R, Gonzalez G, Perez LF, Pena AM, Vanegas LE. Intra-abdominal infection in patients with abdominal trauma. Arch Surg. 2004 Dec;139(12):1278-85; discussion 1285.

23. Turegano-Fuentes F, Caba-Doussoux P, Jover-Navalon JM, Martin-Perez E, Fernandez-Luengas D, Diez-Valladares L, Perez-Diaz D, Yuste-Garcia P, Guadalajara Labajo H, Rios-Blanco R, Hernando-Trancho F, GarciaMoreno Nisa F, Sanz-Sanchez M, Garcia-Fuentes C, Martinez-Virto A, Leon-Baltasar JL, Vazquez-Estevez J. Injury patterns from major urban terrorist bombings in trains: the Madrid experience. World J Surg. 2008 Jun; 32(6):1168-75.

24. Lipsky AM, Gausche-Hill M, Henneman PL, Loffredo AJ, Eckhardt PB, Cryer HG, de Virgilio C, Klein SL, Bongard FS, Lewis RJ. Prehospital hypotension is a predictor of the need for an emergent, therapeutic operation in trauma patients with normal systolic blood pressure in the emergency department. J Trauma. 2006 Nov;61(5): 1228-33.

25. Almogy G, Mintz Y, Zamir G, Bdolah-Abram T, Elazary R, Dotan L, Faruga M, Rivkind AI. Suicide bombing attacks: can external signs predict internal injuries? Ann Surg. 2006 Apr;243(4):541-6.

26. Almogy G, Luria T, Richter E, Pizov R, Bdolah-Abram T, Mintz Y, Zamir G, Rivkind AI. Can external signs of trauma guide management?: Lessons learned from suicide bombing attacks in Israel. Arch Surg. 2005 Apr;140(4): 390-3.

27. Frykberg ER. Medical management of disasters and mass casualties from terrorist bombings: how can we cope? J Trauma. 2002 Aug;53(2):201-12.

28. Walcher F, Weinlich M, Conrad G, Schweigkofler U, Breitkreutz R, Kirschning T, Marzi I. Prehospital ultrasound imaging improves management of abdominal trauma. Br J Surg. 2006 Feb;93(2):238-42.

29. Rozycki GS, Ballard RB, Feliciano DV, Schmidt JA, Pennington SD. Surgeon-performed ultrasound for the assessment of truncal injuries: lessons learned from 1540 patients. Ann Surg. 1998 Oct;228(4):557-67.

30. Soyuncu S, Cete Y, Bozan H, Kartal M, Akyol AJ. Accuracy of physical and ultrasonographic examinations by emergency physicians for the early diagnosis of intraabdominal haemorrhage in blunt abdominal trauma. Injury. 2007 May;38(5):564-9.

31. Dolich MO, McKenney MG, Varela JE, Compton RP, McKenney KL, Cohn SM. 2,576 ultrasounds for blunt abdominal trauma. J Trauma. 2001 Jan;50(1):108-12.

32. Abbreviated Injury Scale (AIS) 2005 Manual: Association for the Advancement of Automotive Medicine (AAAM), 2005.

33. Körner M, Krotz M, Kanz KG, Pfeifer KJ, Reiser M, Linsenmaier U. Development of an accelerated MSCT protocol (Triage MSCT) for mass casualty incidents: comparison to MSCT for single-trauma patients. Emerg Radiol. 2006 Jul;12(5):203-9.

Received: June 23, 2009 / Accepted: August 14, 2009

Address for correspondence:

Dr. Stefan Huber-Wagner

Munich University Hospital (LMU)

Department of Trauma Surgery - Campus Innenstadt

Nussbaumstr. 20

80336 Munich

Germany

Phone +49-89/5160-2511

Fax +49-89/5160-4934

E-mail_stefan.huber@med.uni-muenchen.de 


\section{ApPENDIX}

\section{Relevant, life-saving emergency operations and related ICPM-Codes}

\begin{tabular}{|c|c|c|}
\hline Anatomical Region & Emergency Operation & ICPM-Code \\
\hline Head & $\begin{array}{l}\text { craniectomy, trepanation, evacuation of a cerebral } \\
\text { hematoma, intracranial bleeding control, removal } \\
\text { of intracranial foreign bodies }\end{array}$ & $\begin{array}{l}\text { 5-010.0; 5-010.1; 5-010.2; 5-010.4; 5-010.x; 5-012.0; } \\
\text { 5-012.1; 5-012.2; 5-012.3; 5-012.4; 5-012.x; 5-012.y; } \\
\text { 5-013.0; 5-013.1; 5-013.3; 5-013.4; 5-013.x; 5-013.y; } \\
\text { 5-014.1; 5-020.0; 5-020.1; 5-020.2; 5-020.3; 5-020.4; } \\
\text { 5-020.5; 5-020.6; 5-020.x; 5-020.y; 5-021.0; 5-021.1; } \\
5-021.2 ; 5-021.3 ; 5-021.4 ; 5-021.5 ; 5-021.6 ; 5-021 . x\end{array}$ \\
\hline Thorax & $\begin{array}{l}\text { emergency thoracotomy, open cardiac massage, } \\
\text { pericardiocentesis, intrathoracal bleeding control, } \\
\text { cardiorrhaphy, heart suture/repair }\end{array}$ & $\begin{array}{l}\text { 5-334.0; 5-334.1; 5-334.2; 5-334.3; 5-340.1; 5-340.y; } \\
5-346.0 ; 5-370.0 ; 5-370.1 ; 5-374.1 ; 5-374.3 ; 5-379.0 \\
5-388.4 ; 5-389.4\end{array}$ \\
\hline Abdomen & $\begin{array}{l}\text { emergency celiotomy, spleenic bleeding control, } \\
\text { splenectomy, hepatic bleeding control, subtotal } \\
\text { hepatectomy, renal bleeding control, nephrectomy, } \\
\text { mesenteric bleeding control, abdominal vessel } \\
\text { bleeding control, gastric bleeding control, pan- } \\
\text { creatic bleeding control, diaphragmatic repair, } \\
\text { enterorraphy, intestinal resection, enterostomy, } \\
\text { urinary bladder repair }\end{array}$ & $\begin{array}{l}\text { 5-540.0; 5-541.0; 5-541.4; 5-541.x; 5-541.y; 5-413.0; } \\
\text { 5-413.1; 5-413.x; 5-413.y; 5-419.0; 5-419.2; 5-419.3; } \\
\text { 5-419.4; 5-419.5; 5-419.x; 5-419.y; 5-501.0; 5-501.1; } \\
\text { 5-501.3; 5-501.x; 5-501.y; 5-502.0; 5-502.1; 5-502.2; } \\
\text { 5-502.2; 5-502.5; 5-502.y; 5-505.0; 5-505.1; 5-505.2; } \\
\text { 5-505.x; 5-505.y; 5-553.0; 5-553.1; 5-553.x; 5-553.y; } \\
\text { 5-554.0; 5-554.1; 5-554.y; 5-557.0; 5-524.0; 5-524.1; } \\
\text { 5-502.2; 5-527.1; 5-347.1; 5-347.3; 5-347.x; 5-347.y; } \\
\text { 5-451.x; 5-452.0; 5-454.0; 5-454.1; 5-454.2; 5-454.3; } \\
\text { 5-454.4; 5-454.5; 5-454.6; 5-454.x; 5-454.y; 5-455.0; } \\
\text { 5-455.1; 5-455.2; 5-455.3; 5-455.4; 5-455.5; 5-455.6; } \\
\text { 5-455.7; 5-455.x; 5-455.y; 5-462.0; 5-462.1; 5-462.2; } \\
\text { 5-462.3; 5-462.4; 5-463.2; 5-467.0; 5-440.0; 5-546.0; } \\
\text { 5-546.1; 5-578.0; 5-388.5; 5-388.6; 5-389.5; 5-389.6 }\end{array}$ \\
\hline Pelvis & pelvic clamp, external fixator, plate-osteosynthesis & $5-798.4 ; 5-798.5 ; 5-798.6$ \\
\hline Limbs & major amputation & $\begin{array}{l}\text { 5-862.0; 5-862.1; 5-862.2; 5-862.3; 5-862.4; 5-862.x; } \\
\text { 5-862.y; 5-863.0; 5-864.0; 5-864.1; 5-864.2; 5-864.3; } \\
\text { 5-864.4; 5-864.5; 5-864.6; 5-864.7; 5-864.8; 5-864.9; } \\
\text { 5-864.x; 5-864.y; 5-865.0; 5-865.1; 5-865.2; 5-865.3 }\end{array}$ \\
\hline
\end{tabular}

ICPM, International Classification of Procedures in Medicine (version 1.1). 